\title{
Systemic potency of fluticasone in asthma
}

\section{CrossMark}

To the Editor:

We read with interest the data from MAIJERs et al. [1], suggesting that in a post hoc analysis of trials in oral corticosteroid (OC)-dependent asthma, the majority of the OC-sparing effects of high-dose inhaled corticosteroids are due to their systemic effects. The meta-regression estimates showed a prednisone (Pred) decrease of $4.9 \mathrm{mg}$ per $1.0 \mathrm{mg}$ increase in fluticasone propionate (FP) dose. This was based on the premise from an analysis of two studies where $1.0 \mathrm{mg}$ FP was equivalent to $5.0 \mathrm{mg}$ Pred for cortisol suppression, although this was only calculated in reference to a $10 \mathrm{mg}$ dose of Pred. A ratio of 1.02 was then inferred for the proportion of the OC-sparing effect due to systemic absorption of FP.

In a prospective randomised controlled dose-response comparison of placebo, Pred $(5 \mathrm{mg}, 10 \mathrm{mg}, 20 \mathrm{mg}$ per day) and FP $(0.44,0.88,1.76 \mathrm{mg}$ per day ex actuator) we calculated a relative dose potency for cortisol suppression of $8.5: 1.0 \mathrm{mg}$ comparing Pred versus FP in adult asthma patients [2]. In turn, the calculated systemic absorption ratio for FP would be 1.73 for OC-sparing. Assuming part of the OC-sparing effect of FP is due to suppression of type 2 inflammation, in the same dose-response study the relative dose potency for blood eosinophil suppression was 5.3:1.0 mg, which would result in a systemic absorption ratio of 1.08 for FP [2]. In a meta-analysis of 21 studies the relative dose-related cortisol suppression was 4.3-fold greater for FP than budesonide [3]. We would therefore concur with MAIJERs et al. [1] that use of high-dose FP requires similar considerations as starting maintenance low-dose Pred.

@ERSpublications

Use of high dose fluticasone propionate requires similar considerations as starting maintenance low dose prednisone http://bit.ly/3aLXcjO

Cite this article as: Lipworth B, Kuo CRW, Chan R. Systemic potency of fluticasone in asthma. Eur Respir J 2020; 55: 2000104 [https://doi.org/10.1183/13993003.00104-2020].

Brian Lipworth, Chris RuiWen Kuo and Rory Chan

Scottish Centre for Respiratory Research, University of Dundee, Ninewells Hospital and Medical School, Dundee, UK.

Correspondence: Brian Lipworth, Scottish Centre for Respiratory Research, University of Dundee, Ninewells Hospital and Medical School, Dundee, DD1 9SY, Scotland, UK. E-mail: b.j.lipworth@dundee.ac.uk

Received: 17 Jan 2020 | Accepted: 20 Jan 2020

Conflict of interest: B. Lipworth reports equipment supplied by GSK, grants, personal fees for advisory board work, lectures and consultancy, non-financial support for meeting attendance from AstraZeneca and Teva, personal fees for consultancy from Lupin, Glenmark, Vectura, Dr Reddy and Sandoz, during the conduct of the study; grants, personal fees for consultancy and lectures, non-financial support for meeting attendance from Boehringer Ingelheim, grants and personal fees for advisory board work, consultancy and lectures from Mylan, grants and personal fees for advisory board work and consultancy from Sanofi Regeneron, outside the submitted work; and has a family member who is employee of AstraZeneca. C.R.W. Kuo reports personal fees for meeting attendance from AstraZeneca, personal fees for meeting attendance and lectures from Chiesi, outside the submitted work. R. Chan has nothing to disclose.

\section{References}

1 Maijers I, Kearns N, Harper J, et al. Oral steroid-sparing effect of high-dose inhaled corticosteroids in asthma. Eur Respir J 2020; 55: 1901147.

2 Wilson AM, Lipworth BJ. Short-term dose-response relationships for the relative systemic effects of oral prednisolone and inhaled fluticasone in asthmatic adults. Br J Clin Pharmacol 1999; 48: 579-585.

3 Lipworth BJ. Systemic adverse effects of inhaled corticosteroid therapy: a systematic review and meta-analysis. Arch Intern Med 1999; 159: 941-955. 